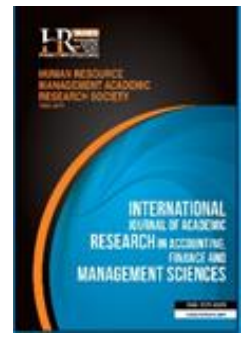

International Journal of Academic Research in Accounting, Finance and Management Sciences

Vol. 8, No.3, July 2018, pp. 224-237

E-ISSN: 2225-8329, P-ISSN: 2308-0337

(c) 2018 HRMARS

www.hrmars.com

To cite this article: Hussaini, U., Bakar, A.A., Yusuf, M.-B., O. (2018). The Effect of Fraud Risk Management, Risk Culture, on the Performance of Nigerian Banking Sector: Preliminary Analysis, International Journal of Academic Research in Accounting, Finance and Management Sciences 8 (3): 224-237,

\title{
The Effect of Fraud Risk Management, Risk Culture, on the Performance of Nigerian Banking Sector: Preliminary Analysis
}

\author{
Umaru HUSSAINI ${ }^{1 \& 3}$, Arpah ABU BAKAR ${ }^{1}$, Muhammad-Bashir Owolabi YUSUF ${ }^{2}$ \\ ${ }^{1}$ Universiti Utara Malaysia, School of Economics, Finance \& Banking (SEFB). \\ ${ }^{2}$ Al Hikmah University, Ilorin, Department of Economics. \\ ${ }^{3}$ Waziri Umaru Federal Polytechnic, Birnin Kebbi. Kebbi State. Nigeria \\ Email: umaruk002@gmail.com
}

\begin{abstract}
Fraud has become the most viable threat to the global economy requiring maximum attention of forensic accountants and traditional auditors, as well as anti-graft bodies worldwide. The primary objective of this paper is to discuss the process of screening, editing and preparation of initial data collected, before any further multivariate analysis of the study regarding the relationship between fraud risk management and risk culture on bank performance. A survey method was employed to administer a total of 417 questionnaires to either the senior officer in the risk management department, internal control department, and branch manager of each bank in the Nigerian banking sector. The questionnaire is a 5 point Likert-scale. The data was analyzed using Statistical Package for the Social Sciences (SPSS) version 23 (v23). The initial data screening and cleaning were conducted as an attempt to fulfill the assumptions of multivariate analysis. Therefore, the present study assessed missing values, outliers, normality test, collinearity test, common method variance, and test of nonresponse bias with the help of SPSS V23. The results have shown that the data satisfied the multivariate analysis assumptions which indicate the fulfillment of conditions for further multivariate analysis.

Key words Fraud risk management, risk culture, performance, Nigeria, banking sector

Received: 20 Sept $2018 \quad$ C The Authors 2018

Revised: 10 Oct 2018 Published by Human Resource Management Academic Research Society (www.hrmars.com)

Accepted: 20 Oct 2018 This article is published under the Creative Commons Attribution (CC BY 4.0) license. Anyone may Published Online: 1 Nov 2018 reproduce, distribute, translate and create derivative works of this article (for both commercial and noncommercial purposes), subject to full attribution to the original publication and authors. The full terms of this license may be seen at: http://creativecommons.org/licences/by/4.0/legalcode
\end{abstract}

\section{Introduction}

Fraud has become the most viable threat to the global economy that requires the maximum attention of the internal control, traditional auditors, forensic accountants, and anti-graft bodies globally (Abdullahi and Mansor, 2018). Its menace has certainly emerged as one of the hindrances to bank performance (AbdulRasheed et al., 2012). In addition, it is a major cost to society (Lee and Fargher, 2013). Levi, Burrows, Fleming, and Hopkins (2007) recently very conservatively estimated that in the UK alone, the impact, extent, and nature of fraud is in the region of $f 14$ billion per annum. Despite the tremendous efforts made by the organizational management, governing bodies in eradicating fraudulent activities, it is indeed discovered that fraud in its various natures continues to grow in frequency, and severity (Coram et al., 2008; KPMG, 2009; Wolfe and Hermanson, 2004). The high level of fraud experienced in Nigeria has now reached an alarming stage. It is so disturbing that the inability of both public and private sector auditors (i.e. external and internal) and traditional auditing method to checkmate fraud has attracted public concerned (Sorunke, 2018).

For instance, in 2017 it was reported that there are 340 cases of fraud perpetrated by staff in the Nigerian banking sector only, which necessitate the dismissal of 286 staffs as a result of fraud and forgeries 
(Illoani, 2018). Fraud is considered as a global phenomenon, as it has universally penetrated both the public and private sectors to the extent that no country is protected from its taint while developing countries suffer the most (Okoye and Gbegi, 2013). Fraud has affected organizational performance, growth, and national development and undermined the corporate and norms and values (Omoolorun and Abilogun, 2017). The main purpose of this paper is to conduct a preliminary analysis of the data collected regarding the relationship between fraud risk management and risk culture on bank performance to satisfy the multivariate analysis assumptions.

When conducting statistical analysis for hypothesis testing, appropriate conclusions can only be drawn when the assumptions guiding the specific analysis are sound (Cruz, 2007). In any multivariate analysis, especially where primary data is obtained from surveys, an initial process of screening and treatment of collected data is a necessary step because it guarantees high-quality analysis that can generally be accepted by the practitioners and academic community by ensuring that the subsequent analyses are valid, such as PLS or other parametric or non-parametric statistics when conducted. It also helps the researchers to recognize any possible violations of the main assumptions regarding the application of multivariate techniques of data analysis (Hair et al., 2010). Pallant (2007) expressed that, before starting any analysis of data, it is essential to check the data set for error because it is very easy to make a mistake in data entry. Tabachnick and Fidell (2007) noted that for the accuracy of data to be guaranteed there is a need for proper proofreading and checking of the data for errors.

Unfortunately, it was observed that researchers had been conducted mostly without initial data screening and preliminary analysis perhaps due to the rigorous activities attached to such process (Hair et al., 2010). Even though, ignoring such process can affect the predictive power of any analysis outcome, because, ignoring the initial data screening would increase the standard error estimates, which in turn influences the regression-based path coefficient negatively (Dijkstra and Henseler, 2015). To achieve accuracy and consistency in any analysis, data screening is one of the essential factors to be given due consideration (Tabachnick and Fidell, 2007). Hence, there is need to examine data through descriptive statistics using computer software. In this way, all the hidden errors that are not easily observed would be revealed (Hair et al., 2010). Additionally, the authors observed that by conducting data examination, researcher gains at least two critical benefits. Firstly, complete understanding of the interrelationships among the variables and this consequently facilitates articulate interpretation of results. Secondly, ability to satisfy the assumptions of multivariate data analysis which is more complex than in univariate analyses.

Based on these, the objective of this paper is to present preliminary analysis employed in finding the effect of fraud risk management and risk culture on the performance of Nigerian banks. The following preliminary data analyses were performed: (i) assessment of missing value (ii) assessment of outliers (iii) normality test and (iv) multicollinearity test (v)common method variance, and non-response test bias (Tabachnick and Fidell, 2007). Conclusively, this study examined issues related to preliminary analysis to have a free error data as recommended by (Hair et al., 2014). The following sections consist of the literature review, methodology, result, and discussion, and then, finally, the conclusion was derived based on the results of the study.

\section{Literature review}

Every business transaction is exposed to the risk of fraud. The danger of fraud has affected not only organizations in a developed economy, but it has also affected developing nations and differs across time as well as places in its magnitude (Inaya, 2016). Perhaps, that is why ACFE in (2010) reported the risk of fraud to be present in almost every business regardless of shape, size, country, and complexity. The risk of fraud could materialize itself in an employee, vendor, client, or management, (Vonya Global, 2011). Ghazali et al. (2014) in their study revealed that fraud is a significant problem in public sector, and the main causes of fraud are economic pressure, poor management practices, and weak response strategies. The survey of 6,337 companies by PricewaterhouseCoopers (PwC) (2016) from the study of 115 countries found that $36 \%$ of the companies experienced fraud in the previous 24 months (2014-2015).The reports further revealed that insiders constitute more than half of the fraudsters (56\%) and thus indicating ineffective risk assessment of staff roles and weak internal controls. 
Unfortunately, many organizations tend to underrate the role of fraud risk management in minimizing the risk of fraud in their businesses (Mat et al., 2013). As banking sector is important in economy, it is imperative to develop an effective fraud risk management procedures to mitigate the adverse effect of fraud in the banking system. Fraud risk management involved the activities in developing and identifying plans for the business to minimize the risk that will arise from the potential and actual cases of fraud (Boateng et al., 2014). Specifically, the activities according to the authors are proactive methods designed to prevent, detect, and respond to fraud at an early stage in the banking sector.

\subsection{Bank Performance}

Performance has been defined variously. For instance, Antony and Bhattacharyya (2010) defined performance as the measure that is used to assess and evaluate the achievement of an organization to create and deliver the value to its internal and external customers. It's also seen as a measure of a firm overall financial strength over a given period which can also be used for comparison of industries in aggregation (Hales, 2005). Therefore, performance can be viewed as a measure of how the organization utilizes their assets to generate revenue from their primary mode of operation.

Various approaches are used to measure performance. For instance, Henri (2004) view performance from objective measures to determine whether the company is profitable, while others such as Elnihewi $e t$ al. (2017) used subjective measures (non-financial). Objective measures use a set of financial ratios or volume measures, thus also referred as financial measures. Financial performance is a measure of company's operations and policies in monetary terms. These results are reflected in the firm's value-added, capital base, return on investment, and return on assets (Gitau and Samson, 2016).

Bank performance, is one of the most relevant constructs in the field, and the construct is commonly used as the dependent variable (Gitau and Samson, 2016) Research in bank performance suffers from problems such as selection of indicators based on convenience, its dimensionality, and lack of consensus (Kaplan and Norton, 2001; Ștefănescu and Logofătu, 2017). Many studies measure bank performance with a single indicator and present this concept as one-dimensional (Chazi et al., 2018; Gitau and Samson, 2016) while other researchers used multidimensionality in measuring bank performance (Cristian and Monica, 2017; Gweyi and Karanja, 2014).

\subsection{Fraud Risk Management}

In the light of the current economic condition, it becomes imperative for a business to re-assess the way of managing their fraud risks. Though, business organizations seem too concentrated on ensuring their survival. However, businesses should also not fail to focus on effective fraud risk management, thereby increasing their weakness to fraud. Therefore, organizations should adopt practical measures that can significantly reduce their vulnerability to fraud (Wells and Gill, 2007). This is in line with Coso (2016) advise that the organization should designs, implements, and maintains fraud risk management periodically. Fraud risk management refers to any methods planned in developing and identifying actions for the organization to minimize risk arising from the potential and actual corporate fraud cases; these include fraud detection, prevention, and response to fraud (Alavi, 2016; KPMG, 2016). This research will use the three dimension of fraud risk management (i.e., preventive, detective, and responsive fraud risk management) in finding the effect of fraud risk management on the performance of banking sector in Nigeria. This is consistent with the work of (Alavi, 2016; Albrecht et al., 2012; KPMG, 2017). The three dimensions are briefly discussed below:

\subsubsection{Preventive Fraud Risk Management Method}

Fraud prevention is the initial stage of a fraud risk management framework, which requires the adoption of suitable strategies that can prevent fraud in an organization. Fraud prevention strategies consist of all procedures, training, policies, actions, and communication that stop fraud from occurring (Albrecht et al., 2012). The best approach to fighting fraud in an organizations is to prevent it from occurring in the first which is mostly on improving the key risk processes indicators (i.e. business environment, operational risk, and internal control environment) (Albrecht et al., 2012). To prevent fraud, measures that limit the opportunity of offenders to commit fraud, and reduce motivation need to be taken (AICPA, 2009). Different measures were put in place for fraud prevention. For instance, the use of anti- 
fraud control mechanism such as segregation of duty, limits and approval authorities, review of customers associate, access control,, implementation and application of security mechanism, and physical security control system (KPMG, 2006).

\subsubsection{Detective Fraud Risk Management Method}

Fraud detection refers to all procedures employed by organizations to detect fraud after it has been committed (NDIC, 2014). Fraud detection strategies are plans implemented to efficiently and quickly detect fraudulent activity by identifying suspicious or frauds that have bypassed the preventive measures so that an organization can take proper corrective action (Australian Standard, 2008). Banks have developed a number of strategies to detect and mitigate fraud. The reason behind any fraud detection system is to identify or detect any potential fraud and reduce subsequent losses. Banking sector has a strong interest in developing strategies of detecting fraudulent activity in time due to its direct impact upon its status as a reputable financial institution, bottom line operating expenditure, and as an institutions customer service delivery with integrity (Edge and Sampaio, 2009).

\subsubsection{Responsive Fraud Risk Management methods}

Fraud risk responses are the measures taken for the corrective purpose to remedy the harm caused by fraud (Ross and Armstrong, 2016). Fraud response strategies significantly affect the occurrence of fraud in commercial banks, therefore the tougher the fraud response strategies, the less the likelihood of fraud (Ogola et al., 2016). A successful fraud incident, depending on its magnitude, may negatively affect the survival of an organization (KPMG, 2010). Therefore, the organization should designs, implements, and maintains fraud risk management periodically (Coso, 2016).

\subsection{Risk culture}

Risk culture is a multidimensional concept that includes risk and culture which are complex scopes (Schmitt, 2017). Definition of culture has been discussed by various researchers. For instance, culture refers to a group of values, norms, beliefs, and understanding which members of organization think is a good thing, which can be adapted to external environment and passed on to new members for coordination within the organization (Nikpour, 2017). While, Fraser et al. (2010) define Risk culture as the system of behaviors and values existing in an organization that assists in influencing risk decisions. Power (2013) is on the view that risk culture is not a separate kind of thing to culture in general but rather a specific kind of framing of the culture problem, allowing general concerns about culture to focus on risk-taking and risk control activities.

The global financial crisis and corporate scandals of 2008 report by pertinent stakeholders, rating agencies, and regulators have highlighted ethical issues in the financial institutions business practices have all conceded that the substantial financial losses incurred by these organizations is as a results of their weak organizational cultures which undermined the effectiveness of their risk management frameworks (Wood and Lewis, 2017). Also, Kpodo and Agyekum (2015) argue that risk culture is the light of the organization's operations. These operations had four sub-variables which include compensation or reward system, effective challenge, prevailing accountability framework, and tone at the top or leadership by example.

\section{Methodology of research}

Prior to conducting the main analyses, the data collected were subjected to preliminary analyses in terms of assessment of missing values, identification of outliers, normality, multicollinearity test, common method variance (CMV), test of non-response bias, and descriptive analysis were conducted to meet the preliminary assumption for further multivariate analysis (Hair et al., 2016).

This is achieved through the use Statistical Package for the Social Science version 23 software (SPSS v23). Samples of 417 were selected from the total population of 1,098 banks in Nigeria through stratified random sampling technique. Hence, 305 useable responses were retrieved from the sample. Results pertaining to each of the six key assumptions stated above are reported. However demographic profile and response rate were also discussed below: 


\section{Results and Discussions}

\subsection{Demographic profile of participants}

Statistically, the descriptive analysis reveals that majority of the participants were male $(61.3 \%)$ while $38.7 \%$ were female. This implies that majority of the bank staff senior officers are male since the percentage of male are higher than the percentage of female in the Nigerian banking sector. This disparity could be as a result of socio-cultural practices whereby female were restricted from attending formal education in some parts of the country. For educational background of the respondents, preliminary analysis revealed that (51.5\%) of the respondents have postgraduate degree as the highest educational attainment, followed by bachelor degree or equivalent with $(45.9 \%)$, diploma or equivalent is $(2.6 \%)$, while none has SSCE or equivalent. The academic qualification of the respondents is quite impressive and attests to the high caliber of staff required in the banking sector for senior officers. The result reveals that most of the participants are branch managers (51.8\%), 30.8\% were risk management senior officers, and $17.4 \%$ were internal control officers. This clearly shows that our target respondents have been achieved. Table 1 below summarize the details:

Table 1. Demographics

\begin{tabular}{lcc}
\hline & Frequency & Percentage \% \\
\hline Gender & & \\
Male & 187 & 61.3 \\
Female & 118 & 38.7 \\
Highest Educational Qualification & & \\
ND/NCE & 8 & 2.6 \\
HND/B.SC & 139 & 45.6 \\
Post Graduate & 158 & 51.8 \\
Department & & \\
Internal Control & 53 & 17.4 \\
Risk Management & 94 & 30.8 \\
Branch Manager & 158 & 51.8 \\
Age & & \\
20-29 & 7 & 2.3 \\
30-39 & 133 & 43.6 \\
$40-49$ & 161 & 52.8 \\
$50-59$ & 4 & 1.3 \\
\hline
\end{tabular}

\subsection{Response Rate}

The response rate of the survey is a significant concern in a study because it ensures the questionnaires collected are valid for data analysis (Hair et al., 2010). In this study, 328 questionnaires out of 417 distributed were retrieved. A reasonably good response rate was achieved as a result of the researcher's persistence through several phone call, reminders, and self-re-visit to the respondents (Traina et al., 2005) and series of follow-up through short message service (SMS) for completion of each questionnaire. Therefore, this makes the response rate of $78.66 \%$, though; out of the 328 collected questionnaires only 305 were found to be useful for further analysis. Twenty three questionnaires were excluded from the analysis due non-suitability of either not duly completed or problems of outliers as explained in table 2. This accounted for $73.14 \%$ valid response rate. According to Sekaran and Bougie(2009), a response rate of $30 \%$ is acceptable for surveys. Henceforward, a response rate of this study is adequate for further analysis.

Table 2. Response Rate of the Questionnaires

\begin{tabular}{clcc}
\hline S/N & \multicolumn{1}{c}{ Response } & Frequency & Percent (\%) \\
\hline 1 & No. of distributed questionnaires & 417 & 100 \\
2 & Completed and returned questionnaires & 328 & 78.66 \\
3 & Unusable questionnaires: & 23 & 5.52 \\
& $\bullet \quad$ Incompleteness and non-eligibility & 14 & 3.36 \\
& - Univariate and multivariate outliers & 9 & 2.16 \\
\hline & Returned and usable questionnaires & 305 & 73.14 \\
\hline
\end{tabular}




\subsection{Preliminary Analyses Tests}

\subsubsection{Data Coding and Screening}

Preliminary data analysis is conducted to detect and correct problems in a data set for the main analysis (Fidell and Tabachnick, 2003). The significance of data screening in any process of data analysis particularly quantitative survey cannot be over emphasized because it provides an excellent groundwork for achievement of a significant result. The output and analysis quality are dependent upon the quality of preliminary data screening (Hair et al., 2010). The returned questionnaires (i.e., 328) were keyed into SPSS v23 variable view page. Each item/question was coded and given name based on its main variable initials and under the same latent construct. For instance, 14 items/questions measuring the type of fraud were coded as TYPEA, TYPEB, TYPEC ...TYPEN. Also, ten items/questions measuring preventive fraud risk management were coded as PFRM1, PFRM2... PFRM10 (e.g., question no. 3 "Fraud prevention training to staffs regularly." is coded as PFRM3). Hence, the same process was used to all other independent variables in the study. Equally, for the dependent variable, which is bank performance (financial and non-financial performance), the same process was employed, and seven questions reflecting the financial performance were coded as FINPERF1, FINPERF2... FINPERF7. While six questions reflecting the non-financial performance were coded as NFINPERF1, NFINPERF2 ... NFINPERF6. For the moderating variable (i.e., risk culture), nine items/questions were coded as RC1, RC2 ... RC9.

\subsubsection{Missing Value Analysis}

Missing value "is one of the most pervasive problems in data analysis, its seriousness depends on the pattern of missing data, how much is missing, and why it is missing" (Tabachnick and Fidell, 2007). It is statistically important to check for missing values before conducting any analytic procedures because some statistical packages (e.g., SmartPLS) will not work even with a single data missing. Furthermore, overlooking cases with missing values could lead to the loss of vital information, which subsequently minimizes the statistical power and increases standard errors (Dong and Peng, 2013). The indication of a missing data is when a respondent failed to deliver answer concerning one or more questions thus making the data collected not appropriate for subsequent analysis (Hair et al., 2010). In view of the effect of missing data in analysis, steps were taken by the researcher to prevent the problem of missing data right from the field of data collection in an effort to decrease their rate. Each questionnaire was thoroughly checked upon receipt to make sure that all questions were properly answered.

While there is no universally acceptable cut-off in the literature regarding the percentage of missing value in a dataset for valid statistical analysis Schafer and Olsen (1998)argued that a missing rate of $5 \%$ or less is inconsequential. After running the data for frequency analysis, only a small number of missing values were detected. The results of the missing values analysis are provided in Table 3.

Table 3. Number and Percentage of Missing Value

\begin{tabular}{lc}
\hline \multicolumn{1}{c}{ Construct } & No of Missing Value \\
\hline PFRM 2 & 02 \\
PFRM3 & 02 \\
DFRM1 & 06 \\
RC3 & 04 \\
NFINPERF4 & 04 \\
Total & $\mathbf{1 8}$ \\
No of Data Points & 53 observed Variables * 305 Respondents $=16,165$ \\
Percentage of Missing Data & $18 / 16,165 * 100=\mathbf{0 . 1 1 \%}$ \\
\hline
\end{tabular}

As shown in Table 3, out of 16,165 data points in the SPSS v23 dataset, 18 were randomly missed, thereby accounting for $0.11 \%$. In particular, preventives fraud risk management had 4 missing value, detectives fraud risk management has 6 , while risk culture and performance has 4 missing values each. Despite the fact that $0.11 \%$ missing value in a dataset, the data is still valid for a meaningful statistical analysis which is less than 5\% (Schafer and Graham, 2002).Tabachnick and Fidell (2007) suggested that the missing value is replaced using mean substitution. Therefore, missing values were treated and replaced with the variable mean option, using SPSS v23. This method is used because it is very easy to be executed 
and time effective. Checking and replacement of missing data is essential in running PLS-SEM which is very sensitive to missing data, and as such, it was adequately checked.

\subsubsection{Assessment of Outliers}

Further data screening involved the treatment and assessment of outliers. Outliers are extreme scores or values of data sets that may significantly affect the analysis and the result of the study (Hair et al., 2010). The presence of outliers in a regression-based analysis data set, can seriously mislead the estimates of regression coefficients and lead to unreliable results (Verardi and Croux, 2008). Two types of outliers namely univariate and multivariate were assessed in this study. The presences of univariate outliers can be detected using either standardized variable values ( $Z$ score) or by using frequency distribution tables such as histograms, box plots, and normal probability plots. The study uses standardized variable values ( $z-$ scores) threshold of \pm 3.29 as recommended by Tabachnick and Fidell(2007) Thus, a total of 9 cases were identified using standardized values as potential univariate outliers. Specifically, these 9 cases identified are presented in Table 4.

Table 4. Outliers identified based on standardized values

\begin{tabular}{cc}
\hline Respondents ID & Item Cases with standardized values exceeding $\mathbf{\pm} \mathbf{3 . 2 9}$ \\
\hline 50 & -4.31435 \\
67 & -3.53317 \\
93 & -4.31435 \\
105 & 4.44915 \\
112 & -4.09112 \\
121 & -4.31435 \\
135 & -4.44918 \\
178 & -3.55317 \\
241 & -3.53317 \\
\hline
\end{tabular}

The univariate outliers were deleted from the dataset because they could affect the accuracy of the data analysis technique. In addition, Mahalanobis distance $\left(D^{2}\right)$ was also tested to locate multivariate outliers. Tabachnick and Fidell (2007) defined Mahalanobis distance $\left(D^{2}\right)$ as "the distance of a case from the centroid of the remaining cases where the centroid is the point created at the intersection of the means of all the variables" (p. 74). Hence, Mahalanobis $D^{2}$ was calculated using linear regression methods in SPSS v23, followed by the computation of the Chi-square value. Given that 53 items were used, 52 represent the degree of freedom in the Chi-square table with $p<0.001$, so the criterion is 90.57 (Tabachnick and Fidell, 2007). This means that any case with a Mahalanobis $D^{2}$ value of 90.57 or more (i.e., for the 53 items) at 0.05 degree of freedom should be removed. However, no single case of a multivariate outlier was recorded. Thus, the remaining 305 responses were thus considered for further multivariate analysis.

\subsubsection{Normality Test}

Normality, in particular, can often be addressed prior to hypothesis testing through data screening procedures. Assessing for normality and factors affecting the shape of the distribution prior to hypothesis testing can help researchers draw more accurate conclusions and can help diagnose potential problems early on what can affect the results of the statistical analysis and assumptions underlying the hypothesis tests (Cruz, 2007). Previous research (Reinartz et al., 2009) has traditionally assumed that PLS-SEM provides accurate model estimations in situations with extremely non-normal. However, this assumption may turn out to be false. It was suggested by Hair, Sarstedt et al. (2012) that researchers should perform a normality test on the data. Highly skewed or kurtosis data can inflate the bootstrapped standard error estimates (Chernick, 2011), which in turn underestimate the statistical significance of the path coefficients (Hair et al., 2012). 
Table 5. Results of Test of Skewness and Kurtosis

\begin{tabular}{ccccccccc}
\hline & Min. & Max. & $\begin{array}{c}\text { Descriptive Statistics } \\
\text { Mean }\end{array}$ & $\begin{array}{c}\text { Std. Deviation } \\
\text { Statistic }\end{array}$ & $\begin{array}{c}\text { Statistic } \\
\text { Statistic }\end{array}$ & $\begin{array}{c}\text { Statistic } \\
\text { Statistic Std. Error }\end{array}$ & $\begin{array}{c}\text { Statistic } \\
\text { Std. Error }\end{array}$ \\
\hline Preventive & 2.60 & 5.00 & 3.96 & 0.51 & -0.05 & 0.14 & -0.08 & 0.28 \\
Detective & 3.17 & 5.00 & 4.09 & 0.38 & 0.30 & 0.14 & 0.24 & 0.28 \\
Responsive & 2.22 & 5.00 & 3.99 & 0.44 & -0.67 & 0.14 & 1.20 & 0.28 \\
Risk Culture & 3.22 & 5.00 & 4.04 & 0.27 & 1.34 & 0.14 & 4.14 & 0.28 \\
Financial & 2.86 & 5.00 & 4.02 & 0.34 & 0.27 & 0.14 & 1.92 & 0.28 \\
Non-Financial & 3.17 & 5.00 & 4.07 & 0.31 & 0.81 & 0.14 & 2.13 & 0.28 \\
Valid N (listwise) & & & & & & & & \\
\hline
\end{tabular}

The values of Skewness are found to be below 2, while the values of kurtosis are below 7 in table 5 above. The range of acceptable values of the Skewness is $<2$ and $<7$ for the kurtosis (Gorondutse and Hilman, 2014). Thus, the values are within the acceptable range. However, Field (2009) added that a large sample decreases the standard errors, which in turn inflate the value of the Skewness and kurtosis statistics. Therefore, it is more important to look at the shape of the distribution graphically rather than looking at the value of the Skewness and kurtosis statistics. On this basis, the present study employed a histogram and normal probability plots to check for the normality of the data collected (Tabachnick and Fidell, 2007).

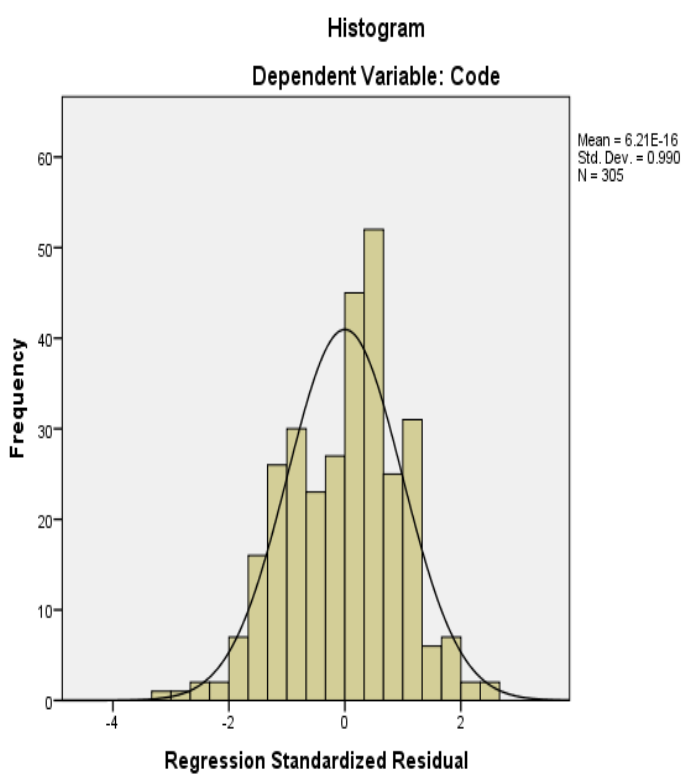

Figure 1. Histogram

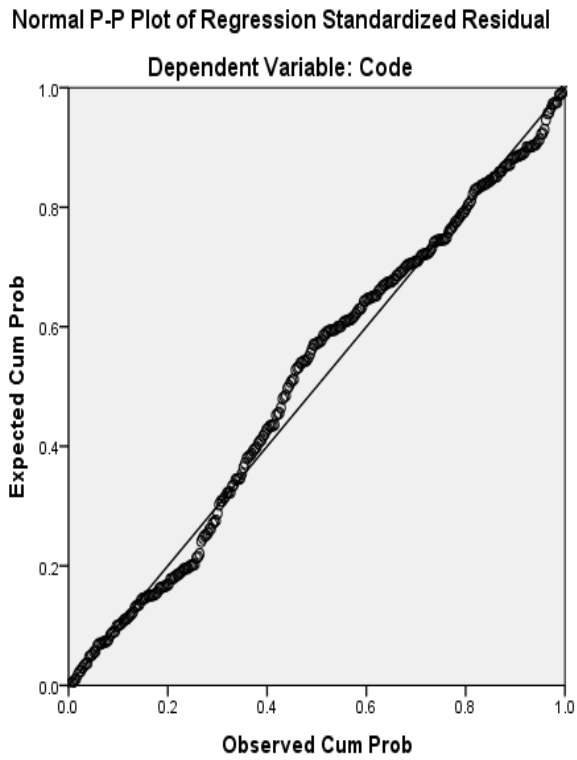

Figure 2. Normal probability plots.

Figure 1 and 2 above revealed data collected confirmed to normal distribution curve indicating that multivariate normality assumptions have not been violated in the present study.

\subsubsection{Multicollinearity}

Multicollinearity refers to a situation in which two or more exogenous latent constructs become highly correlated. Multicollinearity problem occurs when the independent variables are highly correlated to each other (Hair et al., 2010; Tabachnick and Fidell, 2007). The presence of multicollinearity among the exogenous latent constructs can substantially distort the estimates of regression coefficients and their statistical significance tests (Chatterjee and Hadi, 2006). In particular, multicollinearity increases the standard errors of the coefficients, which in turn render the coefficients statistically insignificant (Tabachnick and Fidell, 2007). To detect multicollinearity, two methods were used in the present study as suggested by Peng and Lai (2012). First, the correlation matrix of the exogenous latent constructs was 
examined. According to Hair et al., (2010), a correlation coefficient of 0.90 and above indicates multicollinearity between exogenous latent constructs. Table 4.6 shows the correlation matrix of all exogenous latent constructs.

Table 6. Correlations matrix of the Exogenous Latent Variables

\begin{tabular}{llcccccc}
\hline & & \multicolumn{7}{c}{ Correlation Matrix } \\
Correlation & Preventive & Detective & Responsive & Risk_Culture & Fin_Perf & Non_FinPerf \\
\cline { 2 - 7 } & Preventive & $\mathbf{1}$ & & & & & \\
& Detective & .308 & $\mathbf{1}$ & & & & \\
& Responsive & .229 & .278 & $\mathbf{1}$ & & & \\
& Risk Culture & .209 & .274 & .198 & $\mathbf{1}$ & & \\
& Financial & .301 & .311 & .231 & .286 & $\mathbf{1}$ & \\
& Non-Financial & .267 & .220 & .199 & .228 & .633 & $\mathbf{1}$ \\
\hline
\end{tabular}

**Correlation is significant at the 0.01 level (1-tailed).

Source: Researcher

Following the examination of the correlation matrix for the exogenous latent variables, another way to verify the issue of multicollinearity is through the examination of Variance Inflation Factors (VIF) and tolerance values. This was further examined to detect multicollinearity problem. Hair et al. (2011) suggested that multicollinearity is a concern if VIF value is higher than 5 or, the tolerance value is less than 0.20 . Table 7 shows the VIF values and tolerance values for the exogenous latent constructs.

Table 7. Tolerance and Variance Inflation Factors (VIF)

\begin{tabular}{lcc}
\hline & \multicolumn{2}{c}{ Collinearity Statistics } \\
& Tolerance & VIF \\
\hline Preventive & 0.833 & 1.200 \\
Detective & 0.801 & 1.249 \\
Responsive & 0.876 & 1.141 \\
Risk Culture & 0.864 & 1.158 \\
\hline
\end{tabular}

\section{Dependent Variable: Performance}

The result indicates that independent variables under study do not have multicollinearity problem, because the tolerance values are greater than 0.20 and the Variance Inflation Factors (VIF)range from 1.141 to 1.249 which is acceptable (Hair et al., 2011). Hence, it is concluded that multicollinearity is not an issue in the present study.

\subsubsection{Common Method Variance (CMV) Test}

According to Podsakoff et al. (2003), common method variance (CMV) refers to the variance that is perpetually attributable to the measurement procedure rather than to the actual constructs the measures represent. CMV is important due to its potential of bias when estimating the relationship among the theoretical constructs of the research (Podsakoff et al., 2003). However, there is general agreement that CMV is a major concern for researchers using self-report surveys (Lindell and Whitney, 2001).

Following Viswanathana and Kayandeb (2012), the present study adopted several procedural remedies to minimize the effects of $\mathrm{CMV}$ ). First, to reduce evaluation apprehension, respondents were fully given freedom of choice and freedom of expression assuring that the responses will be kept highly confidential and for the study purposes only. The participants were informed that there is no right or wrong answer to the items in the questionnaire. Second, improving scale items by the elimination of item ambiguity was also used to reduce method biases in the present study. This was achieved by avoiding vague concepts in the questionnaire, and when such concepts were used, simple examples were provided. To further improve scale items, all questions in the survey were written in a simple, specific and concise language.

Third, this study also examined common method variance by applying Harman's single factor test. As suggested by Hulland et al. (2017), all items in this study were subjected to a principal components factor analysis. The outcomes of the analysis yielded 5 factors, explaining a cumulative of $41.80 \%$ of the variance; 
and only $20.74 \%$ of the total variance was accounted by the single factor, suggesting that common method bias does not exist in the present study since it's less than $50 \%$ (Kumar, 2011).

\subsubsection{Test of Non-Response Bias}

Previous studies have established that the non-respondents occasionally differ systematically from the respondents both in behaviors, attitudes, perceptions, and demographics in which any or all of which might affect the results of the study. Non-response bias is the common mistake that a researcher expects to make while estimating sample characteristics because some group of the respondents may be underrepresented as a result of non-response. The issue of non-response bias arises when there is the difference in the answers between non-respondents and respondents (Lambert and Harrington, 1990). Non-response bias can affect the findings of the research and the generalization of the result to the population. Henceforth, there is a need to conduct the non- response bias test to detect this type of error before moving to the main analysis.

With regards to the possibility of non-response bias issue, this research followed a time-trend extrapolation method (Armstrong and Overton, 1977) by comparing the early and late respondents. The respondents were divided into early and late response groups with regards to the five study variables (i.e., preventives, detectives, and responsive fraud risk management, risk culture, financial and non-financial performance). Responses received within one month were classified as early responses while those received after a month were classified as the late responses. Then, an independent samples t-test was conducted for all the study variables to examine if there is any difference between the two groups. As shown in Table 8, below respondents were divided into early and late response groups with regards to the six study variables Looking at the table below, it can be seen generally that the mean and standard deviation for early response and late response are distinctly diverse.

However, the responses were recorded instantly, as the questionnaires were collected from the respondent (Vink and Boomsma, 2008). Most of the respondents in the sample in the study, widely accounted for that is $279(91.5 \%)$ responded to the questionnaire within first month, while the remaining 26 , representing (8.5\%) responded after one month (Table 8 ). Specifically, an independent samples t-test was conducted to detect any possible non-response bias on the main study variables including preventives, detectives, and responsive fraud risk management, risk culture, financial and non-financial performance. Table 8 presents the results of independent-samples t-test obtained. As indicated in Table 8, the results of independent-samples t-test revealed that the equality variance significance values for each of the six main study variables were greater than the 0.05 significance level of Levene's test for equality of variances as suggested by Pallant (2010) and Yin (2009). For this reason, this suggests that the assumption of equal variances between early and late respondents has been taken care up. As such, it can be concluded that non- response bias was not a major concern in the present study.

Table 8. Independent samples T-test for equality of means Leven's test for equality of variance

\begin{tabular}{|c|c|c|c|c|c|c|}
\hline & Non_Response & $\mathbf{N}$ & Mean & Std. Deviation & Std. Error Mean & Sign \\
\hline \multirow[t]{2}{*}{ Preventive } & Early Response & 279 & 3.9086 & .48975 & .02932 & .655 \\
\hline & F Late Response & 26 & 4.4654 & .39994 & .07844 & \\
\hline \multirow[t]{2}{*}{ Detective } & Early Response & 279 & 4.0594 & .36568 & .02189 & .103 \\
\hline & Late Response & 26 & 4.3878 & .41429 & .08125 & \\
\hline \multirow[t]{2}{*}{ Responsive } & Early Response & 279 & 3.9697 & .44009 & .02635 & .457 \\
\hline & Late Response & 26 & 4.2350 & .40774 & .07996 & \\
\hline \multirow[t]{2}{*}{ Risk Culture } & Early Response & 279 & 4.0299 & .26142 & .01565 & .034 \\
\hline & Late Response & 26 & 4.1880 & .30915 & .06063 & \\
\hline \multirow[t]{2}{*}{ Fin. Performance } & Early Response & 279 & 3.9575 & .27635 & .01654 & .822 \\
\hline & Late Response & 26 & 4.7088 & .22671 & .04446 & \\
\hline \multirow{2}{*}{ Non-Fin. Performance } & Early Response & 279 & 4.0149 & .24006 & .01437 & .015 \\
\hline & Late Response & 26 & 4.6731 & .30361 & .05954 & \\
\hline
\end{tabular}




\section{Conclusions}

This paper evaluated the collected data through series of statistical techniques in an attempt to ensure that satisfies the multivariate assumptions. Particularly, as the missing data were thoroughly scrutinized, outliers were detected, treated and removed from the dataset. The study also conducted normality and multicollinearity assessments and data revealed that normality assumptions had not been violated and multicollinearity indicated no significant violation of assumptions in the present study. Thus, the study reports that the data fulfill the multivariate analysis requirements.

\section{References}

1. Abdullahi, R., \& Mansor, N. (2018). Fraud prevention initiatives in the Nigerian public sector: understanding the relationship of fraud incidences and the elements of fraud triangle theory. Journal of Financial Crime, 25(2), 527-544.

2. AbdulRasheed, A., Babaita, I. S., \& Yinusa, M. A. (2012). Fraud and its implication for bank performance in Nigeria. International Journal of Asian Social Science, 2(4), 382-387.

3. ACFE. (2010). Report to the nations: On occupational fraud and abuse. United States of America.

4. Alavi, H. (2016). Mitigating the risk of fraud in documentary letters of credit. Baltic Journal of European Studies, 6(1), 139-156. https://doi.org/10.1515/bjes-2016-0006

5. Albrecht, S. W., Albrecht, C. O., Albrecht, C. C., \& Zimbelman, M. F. (2012). Fraud Examination. South-Western Cengage Learning (Fourth). United States of America: South-Western, Cengage Learning.

6. Antony, J. P., \& Bhattacharyya, S. (2010). Measuring organizational performance and organizational excellence of SMEs - Part 1: a conceptual framework. Measuring Business Excellence, 14(2), 3-11. https://doi.org/10.1108/13683041011047812

7. Armstrong, J. S., \& Overton, T. S. (1977). Estimating Nonresponse Bias in Mail Surveys. Journal of Marketing Research, 396-402.

8. Australian Standard. Fraud and Corruption Control, AS 8001-2008 § (2008). Australia.

9. Boateng, A. A., Boateng, G. O., \& Acquah, H. (2014). A literature review of fraud risk management in micro finance institutions in Ghana. Research Journal of Finance and Accounting, 5(11), 42-52.

10.Chatterjee, S., \& Hadi, A. S. (2006). Regression Analysis by Example (Fourth). John Wiley \& Sons, Inc. https://doi.org/10.1002/0470055464

11.Chazi, A., Khallaf, A., \& Zantout, Z. (2018). Corporate governance and bank performance: Islamic versus non-islamic banks in GCC countries. The Journal of Deverloping Areas, 52(2).

12.Chernick, M. R. (2011). Bootstrap methods: A guide for practitioners and researchers (Second). Hoboken, New Jersey: John Wiley \& Sons, Inc. https://doi.org/9780471756217

13.Coram, P., Ferguson, C., \& Moroney, R. (2008). Internal audit, alternative internal audit structures and the level of misappropriation of assets fraud. Accounting and Finance, 48(4), 543-559. https://doi.org/10.1111/j.1467-629X.2007.00247.x

14.Coso. (2016). Summary of Internal Control-Integrated Framework by COSO :

15.Cristian, S., \& Monica, L. (2017). Measuring performance in organizations from multi-dimensional perspective Annals of the University of TâRgu Jiu, Economy Series, (4), 217-223.

16.Cruz, D. M. (2007). Application of data screening procedures in stress research. The New School Psychology Bulletin, 5(2), 41-45.

17.Dijkstra, T. K., \& Henseler, J. (2015). Consistent partial least squares path modeling. MIS Quarterly (MISQ), 39(2), 297-316.

18.Dong, Y., \& Peng, C. Y. J. (2013). Principled missing data methods for researchers. SpringerPlus, 2(222), 1-17. https://doi.org/10.1186/2193-1801-2-222

19.Edge, M. E., \& Sampaio, P. R. F. (2009). A survey of signature based methods for financial fraud detection. Computers and Security, 28(6), 381-394. https://doi.org/10.1016/j.cose.2009.02.001

20.Elnihewi, I. M., Mohamed, R., \& Hanim, F. (2017). Contextual factors of performance measurement systems design in Libyan commercial banks. Akademia Baru, 7(2), 13-28. 
21.Fidell, L. S., \& Tabachnick, B. G. (2003). Preparatory data analysis. In Handbook of Psychology: Volume 2 Research Methods in Psychology (pp. 115-141). United State of America: John Wiley \& Sons, Inc. https://doi.org/10.1002/0471264385.wei0205

22.Fraser, J., Simkins, B. J., \& Brooks, D. W. (2010). Creating a Risk-Aware Culture. In Enterprise Risk Management (pp. 87-95). Hoboken, NJ, USA: John Wiley \& Sons, Inc. https://doi.org/10.1002/ $9781118267080 . c h 6$

23.Ghazali, M. Z., Rahim, M. S., Ali, A., \& Abidin, S. (2014). A preliminary study on fraud prevention and detection at the state and local government entities in Malaysia. In Procedia - Social and Behavioral Sciences (Vol. 164, pp. 437-444). Kuala Lumpur: Elsevier B.V.

24.Gitau, E. W., \& Samson, N. G. (2016). Effect of financial fraud on the performance of commercial banks: A case study tier 1 banks in Nakuru town, Kenya. International Journal of Economics, Commerce and Management, IV(12), 142-157.

25.Gorondutse, A. H., \& Hilman, H. (2014). Effect of business social responsibility (BSR) on performance of SMEs: Data screening and preliminary analysis. Asian Social Science, 10(8), 103-115. https://doi.org/10.5539/ass.v10n8p103

26.Gweyi, M. O., \& Karanja, J. (2014). The effect of financial leverage on financial performance of deposit taking savings and credit co-operative in Kenya. https://doi.org/10.6007/IJARAFMS/v4-i2/838

27. Hair, J. F. J., Black, W. C., Babin, B. J., \& Anderson, R. E. (2010). Multivariate Data Analysis (7th ed.). New Jersey, USA: Pearson prentice hall.

28. Hair, J. F., Ringle, C. M., \& Sarstedt, M. (2011). PLS-SEM: Indeed a silver bullet. Journal of Marketing Theory and Practice, 19(2), 139-152. https://doi.org/10.2753/MTP1069-6679190202

29. Hair, J. F., Sarstedt, M., Hopkins, L., \& Kuppelwieser, V. G. (2014). Partial least squares structural equation modeling (PLS-SEM ) An emerging tool in business research. European Business Review, 26(2), 106-121. https://doi.org/10.1108/EBR-10-2013-0128

30.Hair, J. F., Sarstedt, M., Pieper, T. M., \& Ringle, C. M. (2012). The Use of Partial Least Squares Structural Equation Modeling in Strategic Management Research: A Review of Past Practices and Recommendations for Future Applications. Long Range Planning, 45(5-6), 320-340. https://doi.org/10.1016/j.Irp.2012.09.008

31. Hales, J. (2005). Accounting and financial analysis in the hospitality industry. ButterworthHeinemann.

32. Henri, J.-F. (2004). Performance measurement and organizational effectiveness: bridging the gap. Managerial Finance, 30(6), 93. https://doi.org/10.1108/03074350410769137

33. Hulland, J., Baumgartner, H., \& Smith, K. M. (2017). Marketing survey research best practices: evidence and recommendations from a review of JAMS articles. Journal of the Academy of Marketing Science, 1-17. https://doi.org/10.1007/s11747-017-0532-y

34.Illoani, F. A. (2018, March 12). NDIC: Fraud cases in banks up by 56.3\% in 2017. Daily Trust Newspaper. Retrieved from https://www.dailytrust.com.ng/ndic-fraud-cases-in-banks-up-by-56-3-in2017.html

35.Inaya, L. (2016). An empirical analysis of social impact of fraud on the Nigerian banking industry. Research Journal of Finance and Accounting, 7(4), 12-17.

36.Kaplan, R. S., \& Norto, D. P. (2001). Transforming the Balanced Scorecard from Performance Measurement to Strategic Management: Part I. Accounting Horizons, 15(1), 87-104.

37.KPMG. (2006). Fraud risk management: developing a strategy for prevention, detection and response. https://doi.org/10.1002/9781119203889.ch8

38.KPMG. (2009). Fraud risk management preventing fraud, detecting waste, responding to abuse, creating transparency, and ensuring accountability.

39.KPMG. (2010). Risk \& Compliance. Nigeria.

40.KPMG. (2016). Global profiles of the fraudster.

41.KPMG. (2017). KPMG survey reveals surge in fraud in Australia. Australia.

42.Kpodo, B., \& Agyekum, K. (2015). The effects of risk culture on organisational performance - The cases of some selected financial institutions in Ghana. International Journal of Science and Research, 4(12), 681-689. 
43.Kumar, R. (2011). Research methodology: A step-by-step guide for beginners (Third). London: SAGE Publications Ltd.

44.Lambert, D. M., \& Harrington, T. C. (1990). Measuring nonresponse bias in customer service mail surveys. Journal of Business Logistics, 11(2), 5-25. https://doi.org/Article

45.Lee, G., \& Fargher, N. (2013). Companies' use of whistle-blowing to detect fraud: An examination of corporate whistle-blowing policies. Journal of Business Ethics, 114(2), 283-295. https://doi.org/10.1007/s10551-012-1348-9

46.Lindell, M. K., \& Whitney, D. J. (2001). Accounting for common method variance in cross-sectional research designs. Journal of Applied Psychology, 86(1), 114-121. https://doi.org/10.1037//00219010.86.1.114

47.Mat, T. Z. T., Nazri, S. N. F. S. M., Fahmi, F. M., Ismail, A. M., \& Smith, M. (2013). Assessing the fraud prevention mechanisms in Malaysian government agencies. Malaysian Accounting Review, 12(2), 141-169.

48.NDIC. (2014). Annual Report and Statement of Accounts,. Nigeria Deposit Insurance Corporation. Abuja Nigeria.

49.Nikpour, A. (2017). The impact of organizational culture on organizational performance: The mediating role of employee's organizational commitment. International Journal of Organizational Leadership, 6(1), 65-72.

50.Ogola, J. O., K'Aol, G., \& Linge, T. (2016). The effect of corporate governance on occurrence of fraud in commercial banks in Kenya. The International Journal of Business \& Management, 4(7), 135-152.

51.Okoye, E. ., \& Gbegi, D. (2013). An evaluation of the effect of fraud and related financial crimes on the Nigerian economy. Kuwait Chapter of the Arabian Journal of Business and Management Review, 2(7), 81-92. Retrieved from http://search.proquest.com.ezaccess.library.uitm.edu.my/docview/ 1415749010? accountid $=42518$

52.Omoolorun, A. J., \& Abilogun, T. O. (2017). Fraud Free Financial Report: A Conceptual Review. International Journal of Academic Research in Accounting, Finance and Management Sciences, 7(4), 83-94. https://doi.org/10.6007/IJARAFMS/v7-i4/3405

53.Pallant, J. (2007). SPSS survival manual: A step by Step guide to data analysis using SPSS for windows (Third). New York: MCGraw-Hill Higher Education.

54.Pallant, J. (2010). Survival Manual A step by step guide to data analysis using SPSS 4th edition (4th ed.). USA: Open University Pres.

55.Peng, D. X., \& Lai, F. (2012). Using partial least squares in operations management research : A practical guideline and summary of past research. Journal of Operations Management, 30(6), 467-480. https://doi.org/10.1016/j.jom.2012.06.002

56.Podsakoff, P. M., MacKenzie, S. B., Lee, J. Y., \& Podsakoff, N. P. (2003). Common Method Biases in Behavioral Research: A Critical Review of the Literature and Recommended Remedies. Journal of Applied Psychology, 88(5), 879-903. https://doi.org/10.1037/0021-9010.88.5.879

57.Power, M. (2013). The apparatus of fraud risk. Accounting, Organizations and Society, 38(6-7), 525-543. https://doi.org/10.1016/j.aos.2012.07.004

58.PricewaterhouseCoopers. (2016). Adjusting the lens on economic crime-Preparation brings opportunity back into focus: Global economic crime survey. https://doi.org/×141

59.Reinartz, W. J., Haenlein, M., \& Henseler, J. (2009). An Empirical Comparison of the Efficacy of Covariance-based and Variance-based SEM. International Journal of Research in Marketing, 26(4), 2017.

60.Ross, P., \& Armstrong, J. (2016). Fraud risk in difficult economies. Canada, USA.

61.Schafer, J. L., \& Graham, J. W. (2002). Missing data: Our view of the state of the art. Psychological Methods, 7(2), 147-177. https://doi.org/10.1037//1082-989X.7.2.147

62.Schafer, J. L., \& Olsen, M. K. (1998). Multiple imputation for multivariate missing-data problems: a data analyst's perspective Joseph. Multivariate Behavioral Research, 33(4), 545-571.

63.Schmitt, E. (2017). Effective risk culture in banks: Responsibilities and boundaries of the risk management. Journal of Economic Literature: G21, G28, G32.

64.Sekaran, U., \& Bougie, R. (2009). Research methods for business: A skill building approach (Fifth). United Kingdom: A John Wiley \& Sons, Ltd, Publication. 
65.Sorunke, O. A. (2018). Forensic Accounting Investigation Techniques and Successful Prosecution of Corruption Cases in Nigeria. International Journal of Academic Research in Accounting, Finance and Management Sciences, 8(3), 37-44. https://doi.org/10.6007/IJARAFMS/v8-i3/4450

66.Ștefănescu, C., \& Logofătu, M. (2017). Measuring organizational performance in a multidimensional perspective. In "Information Society and Sustainable Development. Targu-Jiu, Gorj, Romania: Academica Brâncuşi Publishing House.

67.Tabachnick, B. G., \& Fidell, L. S. (2007). Using Multivariate Statistics (Fifth, Vol. 28). Boston: Pearson Education, Inc. https://doi.org/10.1037/022267

68.Traina, S. B., MacLean, C. H., Park, G. S., \& Kahn, K. L. (2005). Telephone reminder calls increased response rates to mailed study consent forms. Journal of Clinical Epidemiology, 58(7), 743-746. https://doi.org/10.1016/j.jclinepi.2005.02.001

69.Verardi, V., \& Croux, C. (2008). Faculty of business and economics robust regression in stata robust regression in stata. Available at SSRN 1369144. Vigoda-Gadot, 9(3), 439-453. https://doi.org/10.1002/cpp.457

70.Vink, J. M., \& Boomsma, D. I. (2008). A comparison of early and late respondents in a twin-family survey study. Twin Research and Human Genetics, 11(2), 165-173. https://doi.org/10.1375/twin.11.2.165

71.Viswanathana, M. \& Kayandeb, U. (2012). Commentary on " Common Method Bias: Nature, Causes, and Procedural Remedies". Journal of Retailing, 88(January), 556-562. https://doi.org/10.1016/ j.jretai.2012.08.001

72.Vonya Global. (2011). Fraud Risk Management Report. Vonya Global LLC, Chicago.

73.Wells, J. T., \& Gill, J. D. (2007). Assessing Fraud Risk. Journal of Accountancy, 204(4), 63-65. Retrieved from http://search.proquest.com/docview/206787369?accountid=14549\%5Cn http://hl5yy $6 \times 2$ p.search.serialssolutions.com/?genre=article\&sid=ProQ:\&atitle=Assessing+Fraud+Risk\&title=Journal+o $\mathrm{f}+$ Accountancy $\&$ issn $=00218448$ \&date $=2007-10-01 \&$ volume $=204 \&$ issue $=4 \&$ spage $=63 \&$ autho

74.Wolfe, D. T., \& Hermanson, D. R. (2004). The fraud diamond: Considering the four elements of fraud. CPA Journal, 74(12), 38-42.

75.Wood, A., \& Lewis, A. (2017). Risk culture development within the caribbean development bank. The Business and Management Review, 8(4), 221-234.

76.Yin, R. K. (2009). Case study research : design and methods. Applied social research methods series; (4th ed., Vol. 5.). Nashville: SAGE Publications Pvt Ltd. https://doi.org/10.1097/ FCH.0b013e31822dda9e 